\title{
The Research and Application of Critical Discourse Analysis
}

\author{
Xiaoyan Fan \\ Shanxi Normal University, Linfen, Shanxi, China
}

\begin{abstract}
Critical discourse analysis (CDA) reveals the relationship between power and ideology behind language by analyzing discourse. News as an important channel for people to obtain information in their daily life, its objectivity is self-evident, but the ideology contained in it is often ignored by readers. This paper reviews the development and characteristics of critical discourse analysis, and analyzes the critical discourse from four aspects: transitivity, modality, transformation and classification, to explore the ideological and political positions behind the text.
\end{abstract}

Index Term - critical discourse analysis, characteristics, news discourse

\section{INTRODUCTION}

Critical discourse Analysis (CDA), ) aims to analyze the relationship among language, power and ideology, not only about what language is, but also why it is, it is not only interested in the meaning of discourse, but also in how the meaning is produced in discourse. Through the superficial form of language, it reveals the influence of ideology on the text, the reaction of the text to ideology, and how they originate from the social structure and how the power relationship serves it. Critical discourse analysis is a revolt and complement to mainstream linguistics. In the 20th century, the mainstream school of linguistic research was structuralist linguistics and formalistic linguistics. They thought that language was abstract, closed and static. The system of self-sufficiency separates language from society, and puts forward dualistic models of language research, such as language and speech, synchronic and diachronic, referential and diachronic, horizontal aggregation and vertical aggregation, language ability and language use, and so on CDA completely breaks the thought pattern of "dualistic opposition" and links language research with its social function, which makes language research from static to dynamic.

In 1979, R. Fowler first proposed CDA as a language research method in Language and Control. In 1989, the publication of language and Power (Fairclough, 1989) and speech, Power and ideology (Wodak,1989) marked the maturity of CDA. Up to now, CDA has gone through the development process of more than THIRTY years, from budding to growing. This paper will analyze the characteristics of CDA, explore its problems and development trends in the future, hoping to provide some reference for scholars engaged in CDA.

\section{THE Characteristics of CRitical Discourse ANALYsis}

\section{A. The Clarity of the Research Objectives}

Critical discourse Analysis (CDA) focuses on inequality and injustice in society, reveals the ideology and power behind language, and strives to improve it. Critical discourse analysis not only focuses on analysis, but also focuses on criticism, by analyzing the language forms in the text to reveal the relationship among implied languages, power and ideologies and how the ruling class uses language to exercise ideological control and maintain their position of power. The objective of CDA is to explore how discourse communication is implemented and replicated in the socio-political context and how it is used to resist domination, control inequality and the overflow of power in society.

\section{B. The Generality of the Research Scope}

CDA aims to explore the relationship between ideology and power in discourse. Therefore, any explicit or implied power and control relationship in discourse constitutes the research content of CDA. CDA focuses not only on mass discourse and political discourse closely related to social factors such as gender, age, race, class, but also on the power and inequality implied by different social roles in institutional discourse such as education, medical care, and business. Blommaert summarized the research fields of $\mathrm{CDA}$ as: political discourse study, ideology study, race-related immigration discourse study, economic discourse study, advertising discourse and marketing research. Gender studies of media language, institutional discourse, social work discourse, bureaucratic discourse, educational discourse, etc. In such a wide range of research areas, CDA frequently examines topics such as gender discrimination, racial discrimination, employment and judicial inequality, war, nuclear weapons and nuclear power, political strategies and business practices, etc. ( Blommaert,2005)

\section{The Interdisciplinary Nature of the Research Field}


In order to understand the relationship among language, power and ideology, CDA focuses on absorbing the rational core of different disciplines, such as sociology, linguistics, cognitive science and so on. Through the adjustment of different theories, especially sociological and linguistic theories, the integration of theories is carried out. Because the task of critical discourse analysis is to study the insufficient analysis of text by sociological theory and the insufficient exploration of sociological theory by linguistic theory, and to combine the two perfectly through "internalization".

CDA draws on relevant sociological theories, for example, CDA draws on Gramsci's hegemonic theory, and argues that civil society relies on hegemony, that is, to maintain the current system with the consent or acquiescence of most people. It is emphasized that ideology can control all members of society effectively, and pay attention to how the mass media such as television, newspapers and periodicals control the members of society. Foucault's discourse theory makes critical discourse analysts realize that discourse and power are dialectical isomorphism. Discourse is not only the product of power but also the component of power. At the same time, according to Harbermas's communicative behavior theory, critical science must pay attention to the relationship between language and social communication, and its discourse evaluation criteria provide a useful reference for critical discourse analysis.

In the field of linguistics, CDA mainly draws on the theory of systemic functional linguistics, which is a multifunctional theory linking language and social context, and is very suitable for discourse analysis. Therefore, systemic functional linguistics is concerned about the phenomenon that language, as a "social symbol", is controlled by the social structure while at the same time constructing the society. Functional linguistics provides a solid analytical basis for CDA and enables criticism to take root in linguistic analysis. CDA not only absorbs sociological theory and systemic functional linguistic theory, but also draws on the research achievements of social semiotics, cognitive science, psychology, pragmatics, stylistics, rhetoric and conversational analysis.

\section{The Diversity of the Research Schools}

Because of the different theories of reference, there are different schools in CDA, such as Fairclough's three-dimensional analytical framework, Wodak's discourse history analysis method and van Dijk's social cognitive research model. These three schools explore the hidden power and ideology behind language from different angles, and provide a multi-and comprehensive perspective for critical discourse analysis.

The three-dimensional analysis framework of Fairclough tries to put forward a theoretical paradigm for CDA based on the functional linguistics of the system. Fairclough regards text, communication and social context as the three main elements of discourse. Based on this, he puts forward a three-dimensional analysis framework, that is, discourse, discourse practice and social practice. Discourse is the product of discourse practice, and this process includes the generation communication and acceptance of discourse. On the basis of this, this paper puts forward three levels of critical discourse analysis: describing the formal structural features of discourse, that is, text analysis, , including the analysis of language use and discourse communication, often using systemic functional grammar for linguistic description. Explaining the relationship between discourse and discourse practice, and this process is the intermediary of description and interpretation. Expounding the relationship between discourse practice and its context, analyzing the phenomenon of power and inequality, and revealing how power and ideology work. Then, Fairclough \& Chouliar-aki puts forward five steps of critical discourse analysis. Firstly, locking down a social problem related to discourse; Secondly, determining the difficulties in dealing with the problem, through the analysis of the network of social practice in which the discourse is located, the analysis of the relationship between the discourse and the other components of the social practice, and the analysis of the discourse itself, the difficulties in dealing with the problem are determined; Thirdly, considering whether to solve the problem involving social order; Fourthly, determining the solution of the problem; Fifthly, making a critical reflection. Fairclough's discourse analysis model has a strong operability, it is the most systematic and perfect in the critical discourse analysis school, and provides a valuable reference for the study of mass discourse.

In Wodak's discourse-historical analysis method, discourse is studied in a specific social and historical context. Wodak defines discourse as "representing the meaning of a particular field of social practice from a particular point of view," which is similar to Fairclough's definition of discourse. Wodak \& Weiss believe that social phenomena is a complex phenomenon. It cannot be simply understood as causality. There is a dialectical relationship between discourse practice and its behavior field. Context is an important factor in the process of construction and construction. The analytical framework divides the context into four levels: The relationship between language and context, the relationship among Segment, text, genre and inter discourse, the external sociological variables of language and the institutional framework involved in context, a broader context of social history. The four levels of context correspond to the four analytical levels of the analytical framework: linguistic analysis, discourse theory, moderate degree theory and grand theory. The first level is descriptive, and the other three levels of analysis aim at constructing a context theory. Wodak's view and method of pragmatics have developed four-step analytical strategies: first, to identify a discourse theme related to words such as race or discrimination; Second, to examine the discourse strategies used in the discourse; third, to analyze the linguistic characteristics; fourth, to carry on the formal analysis of the language in a specific context.

Van Dijk advocates the social cognitive model and constructs the triangle pattern of the "discourse-cognitive-Society", According to van Dijk, discourse and social structure are connected by the medium of social cognition, this social cognition emphasizes the sociality and collectivity of human cognition, often refers to more abstract ideas, belief 
systems and ideologies, etc., which are acquired and put into practice mainly through discourse, and are constantly corrected in practice. Discourse is a communicative event. It is a form of expression of various meanings, including interactive discourse, writing text and related gestures, facial expressions, print layout and other symbols.

\section{The ApPliCATiOn OF CDA in NeWs Media}

Halliday's systematic functional grammar is devoted to the study of the context and socio-cultural background of the discourse, thus becoming the basis of many critical approaches and methods of discourse analysis, and plays a leading role in the critical analysis of public discourse. In his view, there are three major metafunctions, namely, ideational function, interpersonal function and textual function, which constitute the meaning potential of language. Conceptual function refers to the speaker's experience of the world and its various phenomena, interpersonal function refers to the speaker's attitude and evaluation of the related phenomena, which is used to establish a relationship between the speaker and the listener, and the textual function is the tool of the above two functions. The speaker can speak a discourse that can be understood by the listener through the textual function, which can link the discourse with the context and context in which it is generated. According to critical linguists, language is inextricably related to society, and the speaker's choice of discourse is governed by some principles intentionally or unintentionally. In other words, the sentence itself carries and expresses a certain social significance. Therefore, the form of language depends on its social function, and the difference of structure not only reflects the difference of ideology, but also helps to maintain and strengthen the difference. However, it is not easy to understand the intentions behind news coverage in all kinds of media. Because ideology is not a concrete information content, but an abstract level, it is implicit in the information, so it becomes rather subtle and difficult to detect. However, the nature of news media serving different ideologies and values is unchanged. This article will analyze and explore the ideology behind the news from four aspects.

\section{A. Transitivity}

Transitivity is the main element of conceptual function. In systemic functional language, transitivity refers to the expression of what people see and hear in language. The speaker's choice of process function component and embodiment means is influenced by ideology to a great extent. Halliday classifies transitive processes into six types: material process, mental process, relational process, behavioral process, verbal process and existential process. The following is a discussion of the application in media coverage.

Material process is a process of doing something for another entity. The executor of the process is known as the enabler, and the other major participants call it the target. A material process is a truly objective record of facts and circumstances.

(1). China will prosecute a former senior provincial official for corruption after an investigation found he illegally accepted gifts and abused his power.

(2). Under Mr. Xi, the party has carried out an extensive crackdown on corruption that has seen more than 1.5 million officials investigated in the past five year.

Examples (1) and (2) use a large number of dynamic verbs, such as "prosecute" and "carry out", in line with the requirements of objectivity in journalism, and most of them are in line with the facts when reporting on China's anti-corruption reality and achievements, showing the truth to the public objectively and impartially. The selection of material quality reflects the objective attitude of foreign media towards anti-corruption in China to a certain extent, and helps readers to understand the reality of anti-corruption in China positively and objectively.

Verbal process is the process of communication of information, used to express warnings, explanations, etc. It is a symbolic relationship formed in human consciousness, and presented in the form of language. One of the prominent features of news discourse is to quote the source of the message, which mainly includes two ways: the direct source and the indirect source.

(3). General Fang's "ideals and convictions had been shaken, he abandoned the mission of the party and degenerated politically, becoming economically rapacious," said an editorial published in the Liberation Army Daily on Wednesday. His misdeeds, it added, had"seriously tarnished the image of the party, the military and leading officials."

When reporting the anti-corruption problem in China, the New York Times directly quotes the words of relevant personnel and institutions, especially the selection of Chinese authorities and Chinese authoritative figures or media, which first ensures the authority and credibility of the report. For example, directly quoting an editorial published in the PLA Daily, the organ of the Central military Commission (CMC), clearly pointed out Fang Fenghui's corrupt and illegal acts, and enhancing the dialogue of the report. First of all, readers are exposed to relatively objective and real one-hand corpus information, which is helpful for readers to make corresponding examination and objective judgment on corruption in China according to their own understanding. Although there are a large number of indirect references, the use of relatively pertinent words, such as said, added,reported, accounts for most of the verbal process.

The relational process denotes the process of the relationship between things, which is divided into two categories: attributive and identifying. The attribution class is composed of the carrier, attribute and the verb representing the relationship, and the recognition class is composed of the identified, identifier and the verb representing the relationship. The two types can be further divided into three modes: the intensive, circumstantial and the possessive.

(4). Sun' s case is testimony to the "fearless spirit and unwavering resolve" of the campaign against graft. 
(5). "Grave violations of discipline" is a vague phrase that can include corruption or disloyalty to the party.

The identified person is "Sun 's case," and the identifier is "fearless spirit and unwavering resolve." the New York Times showed the reader the confidence and determination in the process of anti-corruption in China with regard to the case of Sun Zhengcai. To some extent express its positive attitude to the anti-corruption work. The New York Times makes full use of the broad concept of "Grave violations of discipline" in the title of the report that Sun Zhengcai is accused of, in an attempt to create an illusion among readers and make them feel that Sun Zhengcai has been subject to dismissal investigation just because of the violation of discipline. To stigmatize China's image, its language strategy allows hidden ideology to be exposed.

Mental process is a process of perception, which includes perception, cognition, emotion and will. The two main participants in the psychological process are the sensor and the phenomenon. The mental process shows the perception of what happened, which is helpful to construct the inner state, ideology and value orientation of the sensor.

(6). I have only myself to blame and deserve my punishment. I completely accept (the charge). I sincerely admit my guilt and express regret.

The sensor is "corrupt official Sun Zhengcai", here through the mental process to express his own series of psychological experiences, "blame", "completely" sincerely "and so on reflect the perception of deep guilt and regret.

\section{B. Modality}

According to Halliday, one of the important components of interpersonal function is that the speaker makes a judgment about his or her proposition or expresses an individual's will in his proposal, and that either is realized by a modal system.(Halliday,2000). Fowler believes that modality is the expression of an individual's willingness, responsibility, and anticipation for the event. In news reports, modality can reflect the views and positions of the reporter, and can be realized by modal verbs, modal adverbs, modal adjectives and so on. Although we generally believe that fairness and objectivity are the requirements of news reports, no matter how objective they are, they inevitably reflect the author's personal attitudes and ideologies, which are often achieved through modal system. Halliday classifies modality into two categories: modalization and modulization. Modalization is often used to express probability and frequency, and modulization is used to express obligation and will. Through the analysis of the modality in the news discourse, we can find out the basic position of the speaker.

(7). Companies are required to report any potential problems to the safety commission, which sets industry standards and does some news testing.

In this example, "are required to" embodies a modal sense of responsibility. With the help of passive voice, the author implies that the company has the responsibility to expose its potential problems to the public. Passive sentences are often the most effective way to cover up the perpetrator. In this case, the reporter blurts the actors who act to avoid referring to the responsibilities they carry.

(8). They included Chinese-made toys that either had excessive amounts of lead paint or had small magnets that could easily be swallowed by children.

"Easily" is a modal adverb that expresses a tendency. If it is omitted, it will not fully show the evil nature of the matter and the necessity of recalling toys made in China.

(9). Maybe this was corruption or substandard work, or perhaps things were put into place too fast.

In example (9), "maybe" and "perhaps" express uncertainty and possibility. The uncertainty and feasibility of the author not only implied that the sentence was true, but also influenced the reader's judgment of the event. In addition, the use of the derogatory word "substandard" reveals the author's doubts about the safety of China's railways.

(10). I've never heard of lightning doing that, but if it did, everything else would stop too. And the signal system should keep trains at a safe distance.

The "never" in example (10) expresses the speaker's surprise, but it is in fact a complete negation of the results of the investigation of the accident in China; The use of the subjunctive words "did" and "would" expresses the speaker's subjective view, which is the main idea of the speaker's virtual view. "should" means that the signal system should keep the two cars at a certain distance, but it doesn't. This kind of information misleads the reader, makes the reader feel that China's railway is unsafe, to some extent also tarnished the image of China.

As can be seen from the above examples, foreign media, in expressing their personal attitudes and ideologies, try to avoid the use of words such as "I think"” in my opinion" and more often use modal verbs such as "should", "may" or "could" to express possibilities, frequencies, and tendencies, responsibility, etc. Therefore, Chinese readers should have the consciousness of critical discourse analysis, which can avoid being controlled by their ideology, so that they can understand the content of the report more deeply.

\section{Transformation}

Transformation is a part of grammatical metaphor in systemic functional grammar. Grammatical metaphor is the possibility of re-setting the relationship between wording and meaning, which refers to expressing things in one common form but being expressed in another grammatical form. It is one of the main resources to extend the potential of linguistic meaning. The most commonly used forms of transformation are nominalization and passivation. Nnominalization refers to a speaker who could have expressed a certain meaning in a verb structure or sentence, but used a noun or noun phrase. It can create a non-personification effect, weaken the sense of action and enhance the 
objectivity of the text. Passivation is a means of thematizing, which moves the object component to the beginning of the sentence, allowing the object to act as a marked theme to highlight the message expressed by the component (Xin Bin, 2005). Passivation highlights the subject by deleting the action implementer, emphasizing the information to be expressed, and providing convenience for disguising the causality and the actor.

(11). The government's only explanation for Saturday's accident has been that a lightning strike

disabled equipment.

(12). Immediately after the accident the government dismissed three more railway officials without explanation, and announced a thorough investigation into its cause.

In examples (11) and (12), "explanation" and "investigation" are the noun forms of the verbs "explain" and "investigate" respectively. The author uses nomenclature to blur the subject, time and extent of the "explanation" and "investigation", so that the information conveyed to the reader is not comprehensive, and the reader may have one-sided understanding of the interpretation and investigation of the accident by the Chinese government. And then influence China's international image.

(13). In China, a torrent of public criticism continued Tuesday, with bloggers and citizens asking why the government was not more forthcoming about the cause of the crash, why parts of the wreckage were buried at the site and why a toddler was found alive in the wreck even after railway authorities had said there were no further signs of life.

(14). A railway communications officer, identified only as Mr. Liu, told The Beijing Times that after the accident, he was sent to check the communications system of the first train.

In example (13), "were buried" is used to blur the time of "burying" and the subject of order burying, which leads the reader to assume that the burying is directed by the Chinese government; The subject of "was found" is "toddler", highlighting the fact that babies are the subject of passive voice, indirectly expressing the cruelty of the accident, and also implying a message that the Chinese Government does not attach importance to human rights. This is also a distortion of the image of China. In example (4), "was sent" could have been used to express "dispatch" in an active voice, but the passive voice was used here to mask the action of dispatch and its implementers. That is, who sent him to check the signal of the first car. The author omits the main information and only conveys to the reader the message of "someone to check", thus affecting the objectivity of the facts and embodying the influence of the western media on the public imperceptibility.

\section{Classification}

Classification refers to the use of language to give order to the outside world. The text classification system refers to the naming and description of people and things in the text, mainly through the choice of vocabulary. Classification is the most basic cognitive style of human beings. Language is not an objective classification tool, people use it to label things not necessarily reflect the inherent characteristics of things, but will be affected by people's cognitive level and ideological and emotional sound. That is, different views of things and experience will lead to different classification principles. Compared with other such words, the classification function of nouns is especially noteworthy. Nouns have a high degree of abstractness. They usually classify a lot of things according to only one or two characteristics, and in turn give each member the full connotation of such things. The text classification system refers to the naming and description of people and things in the text, mainly through the choice of vocabulary. Classification is the most basic cognitive style of human beings. Language is not an objective classification tool, people use it to label things not necessarily reflect the inherent characteristics of things, but will be affected by people's cognitive level and ideological and emotional sound. That is, different views of things and experience will lead to different classification principles. Compared with other such words, the classification function of nouns is especially noteworthy. Nouns have a high degree of abstractness. They usually classify a lot of things according to only one or two characteristics, and in turn give each member the full connotation of such things.

(15). China has held a lavish parade in Beijing to make the defeat of Japan in world War Two.

We can find that the word "lavish" is extravagant in the Longman Dictionary, and the reviewers use only one word, lavish, to illustrate the meaning of the Chinese military parade. In this way, news reports depict China as extravagant and extravagant as ancient China. From the choice of words to prove the so-called "China threat theory."

(16). we are not huge fans of military parades, showing off shining new aggressive equipment, in general.

The author uses the word "aggressive" to describe China's so-called aggressive image. In the Oxford Dictionary, "aggressive" means "offensive". Therefore, the term has a strong negative meaning, undoubtedly saying that China has an aggressive heart, that is, the so-called "China threat theory", and obviously this is not in line with the reality.

(17). Pollution in China's Air Creates Concern About Beijing Olympic Games.

The successful hosting of the Olympic Games has always been a good wish of the Chinese people. However, the western media has distorted their reports on the Olympic Games and destroyed the image of the Chinese government. They have completely lost their fair and objective journalistic professional ethics. From the noun of "concern", we can see the suspicion and incitement of the western mainstream media to host the Olympic Games in China. The Western media is not looking at the efforts of the whole of China to successfully host the Olympic Games from an objective point, but is using a microscope to expand the problems facing China. And finally achieve the goal of inciting other participating countries to worry about China's competition environment, thus adversely affected China.

(18). Shanghai's Expo trials get crowded, rocky start. 
Following the successful hosting of the 2008 Olympic Games, the successful hosting of Expo 2010 has become a good wish of the Chinese people. At a time when overseas Chinese and Chinese from all over the world are eager and expected to make efforts for the Expo, some western medias have misrepresented the Expo with prejudice, thus undermine the image of the Chinese government. From the two nouns of "crowded" and "rocky", It is not difficult to see the biased reports of China hosting the World Expo by the western mainstream media.

Therefore, when we read the news reports of western media, we should learn to analyze the skills and means of vocabulary use and choice in news English, so that we can recognize the values of the western media and its propaganda purpose behind it.

\section{CONCLUSION}

After more than 30 years of development, CDA has achieved fruitful results and contributed greatly to language research. It clearly explains the dialectical relationship between language and society, and deepens people's understanding of the interactive relationship among language, power and ideology. At the same time, CDA has been controversial because of its existing problems. In the face of questioning and criticism, linguists continue to explore new theories and methods to promote the development of critical discourse analysis in an in-depth direction.

\section{REFERENCES}

[1] Blommaert. (2005). Discourse: A Critical Introduction. Cambridge: Cambridge University Press.

[2] Caldas-Coulthard, C. \& M. Coulthard (Eds.). (1996). Preface Text and Practices: Readings in Critical Discourse Analysis. London: Routledge.

[3] Chouliamaki, L. \& Fairclough, N. (1999). Discourse in Late Modernity: Rethinking Critical Discourse Analysis. Edinburgh: Edinburgh University Press.

[4] Fairclough N. (1989). Language and Power. New York: Longman.

[5] Fairclough N. (1995). Critical Discourse Analysis: the Critical Study of Language. New York: Longman Publishing.

[6] Fairclough N. (2003). Analysis Discourse: Textual Analysis for Social Research. London and New York: Routledge.

[7] Foucault. (2001). Power, Knowledge and Discourse. In Wetherell Taylor and Yates. Discourse Theory and Practice. London: Sage Publications .72-81.

[8] Fowler, R. (1979). Language and Control. London: Routledge and Kegan Paul.

[9] Halliday, MAK. (2000). An Introduction to Functional Grammar. Beijing: Foreign Language Teaching and research Press.

[10] Harbermas. (2003). Moral Consciousness and Communicative Action. Beijing: Business Press.

[11] Sun Jin. (2004). Research on the Theory of Cultural Hegemony. Beijing: Social Science Literature Press.

[12] Van Dijk. (1998). Ideology: A Multidisciplinary Study. London: Sage.

[13] Van Dijk,T. (2001). Multidisciplinary CDA: A plea for diversity. In R. Wodak \& M.Meyer (Eds.). Methods of Critical Discourse Analysis. London: Sage Publications, 629-634.

[14] Weiss G, Wodak R. (2003). Critical Discourse Analysis Theory and Interdiscipliaity. London: Palgrave Macmillan.

[15] Wodak, R. Language. (1989). Power and Ideology: Studies in Political Discourse. Amsterdam: John Benjamins.

[16] Xin Bin. (2005). Critical Linguistics: Theory and Application. Shanghai: Shanghai language Education Press.

Xiaoyan Fan was born in LinFen, China in 1994. She received her undergraduate degree in English from Datong University, China in 2001.

She is currently a graduate student in the School of Foreign Languages and Applied Linguistics, Shanxi Normal University, Linfen, China. 